\title{
Supporting Online Learning with Games
}

\author{
JingTao Yao DongWon Kim Joseph P. Herbert \\ Department of Computer Science \\ University of Regina \\ Regina, Saskatchewan, Canada S4S 0A2 \\ E-mail: \{jtyao, kim263, herbertj\}@cs.uregina.ca
}

\begin{abstract}
This paper presents a study on Web-based learning support systems that is enhanced with two major subsystems: a Webbased learning game and a learning-oriented Web search. The Internet and the Web may be considered as a first resource for students seeking for information and help. However, much of the information available online is not related to the course contents or is wrong in the worse case. The search subsystem aims to provide students with precise, relative and adaptable documents about certain courses or classes. Therefore, students do not have to spend time to verify the relationship of documents to the class. The learning game subsystem stimulates students to study, enables students to review their studies and to perform self-evaluation through a Web-based learning game such as a treasure hunt game. During the challenge and entertaining learning and evaluation process, it is hoped that students will eventually understand and master the course concepts easily. The goal of developing such a system is to provide students with an efficient and effective learning environment.
\end{abstract}

Keywords: Web-based learning support systems, intelligent search engine, online learning, game-based learning.

\section{INTRODUCTION}

The Internet has emerged as a major and perhaps eventually the major worldwide communication channel for information, knowledge, and services. ${ }^{5}$ The impact of the great changes of Internet technology can be seen in all aspects of people's lives. The impact to teaching and learning may be even greater. The Web can perhaps be viewed as a knowledge repository. Its ease of use and availability enable people to enjoy surfing the Internet. Furthermore, today's mobile devices increase its connectivity and make it more convenient for people to use the Internet.

The Internet has led to the advances in computer technologies, especially the World Wide Web (Web). The Web provides a distributed infrastructure for information processing with good accessibility and easy interfaces. ${ }^{28}$ It makes the possibility to enhance traditional computerized support systems into further user-friendly systems. ${ }^{28}$ It triggers the movement of the support systems to the Web platform with Web technology. ${ }^{28}$ Web-based support systems are re-designed or modified systems of the traditional computerized support systems which support human activities by using Web technology. ${ }^{26,28}$ For instance, one of the most popular and successful computerized support systems are decision support systems. If people develop the decision support systems employing the Web technology, those systems become Web-based decision support systems. ${ }^{19}$

Likewise, if people take into account of learning, the learning support systems combined with Web technology can intuitively be called Web-based learning support systems (WLSS). ${ }^{7}$ Mirroring the increased usage of the Web, WLSS also have grown in popularity. WLSS not only support teachers and students for education, but also conduct education using their own teaching methods on the Web. WLSS have no limitations regarding time and place to learn. WLSS become important alternatives to traditional methods of learning, although occasionally learners may not benefit much due to less human interaction. ${ }^{13}$

The current research aims to incorporate a game component to WLSS. The motivation of this type of study is a key to the success of learning. Learning games enable students to be motivated to study. ${ }^{20}$ While playing a game, a player is not likely to quit from what he is confronted within the game. Games provide with players challenges and entertainment. The graphics, sounds, and storylines can help players become interested in games. But the most attractive thing to players is the appropriate levels of difficulty while removing frustration. These interesting things stimulate a kind of motivation to keep playing the games. The learning games with the motivating properties encourage students to learn while removing the tediousness of online learning. 
We present a study on designing a WLSS, which is armed with a Web-based learning game and has support from a learning-oriented Web search in this paper. The Web-based learning game employs a treasure hunt as a game to be adapted for learning. The treasure hunt provides a good model for a game of learning and it stimulates the learners' motivation for learning. It enables students to review their studies and to conduct self-evaluation tests. While playing the learning game, it is hoped that students can ultimately understand and master the course concept by trials and errors. The learning oriented Web search subsystem is a Web-based information retrieval support system for learning. ${ }^{27}$ It furnishes students with relevant documents based on each student's background knowledge.

\section{ONLINE LEARNING AND WEB-BASED LEARNING SUPPORT SYSTEMS}

Online learning is any method of using electronic communications and information technology to fulfill the education goal. The learning contents can consist of various forms of multimedia like audio, graphics, animation, or video. Such contents enable students to have motivation for learning as well as help students easily understand what they are learning. ${ }^{18}$ In addition to the student friendly and eye-catching contents, online learning has no limitations on time and place of learning. Once the learning contents are created, students can use the material at anytime, anywhere. It also allows students to take courses in a cost effective learning environment. ${ }^{11}$ Such online learning increases the chance for education being available to everyone who is not available at class time or seeks courses at a reasonable price. ${ }^{14}$

Traditional methods of learning provide a teacher-centered form of education and group learners in a conventional classroom. ${ }^{7}$ It is almost impossible for an instructor to satisfy all requirements of all students with her lecture allotment in such case. Normally, a lecture is prepared for average students with average background knowledge of the lecture topic. It is also very difficult to measure each student's understanding of taught contents, even though the instructor takes into account student feedback (quizzes, exams, and assignments) in the lecture. One of the key barriers for traditional teaching is that learning mostly depends on limited time and fixed place.

On the other hand, online learning can provide a student-centered form of education and individual learning. ${ }^{7}$ A student can choose the most suitable space for him based on his background knowledge. He can replay the learning contents until he fully understands. He can skip some contents that he is already familiar with. If he has some questions in his online class, he can easily find assistance from groups of teachers and other students by using a communication tool supplied by the online learning system. He can measure his understanding of the class by using various types of tests at any time. Therefore, online learning is considered as one of means to seduce the disadvantages portrayed by the traditional methods of learning.

Web technology provides effective ways of implementing online learning. The Web offers good accessibility and a user-friendly interface, which is easy to learn and to use. The Web is capable of delivering a variety of information such as text, audio, graphics, animation, and video. It is very important to bring student-friendly content. The advantages of the Web enable online learning to incorporate Web technology in order to accommodate and deliver the learning content. In fact, WLSS has become one of most suitable frameworks for the implementation of online learning. ${ }^{10,29}$

In the design of WLSS, the main features to be considered are 1) to encourage users in communicating with each other, 2) to deliver adapted contents based on students' knowledge, 3) to provide an interactive interface, and 4) to evaluate students' learning process. ${ }^{7}$ Furthermore, it is important to include a feature that stimulates the motivation of learners. In particular, we propose a WLSS with a game component. Three views, namely, teachers, students, and administrators should be considered in a WLSS. ${ }^{7}$ The teacher considers WLSS as a convenient tool to create and modify learning contents, while the student may regard WLSS as a learning support tool containing a variety of learning contents. On the other hand, the administrator may use WLSS to maintain the system for updating content and information about the users.

\section{WEB SEARCH ENGINES AND WEB-BASED LEARNING GAME}

\subsection{Web Search Engines}

There are a lot of Internet-enabled applications and services available. One of the primary tasks of the Internet is for information retrieval. ${ }^{8}$ On the Internet, there are numerous Web pages that are connected with each other by hypertext links. Suppose that one clicks hypertext links on a single Web page and follows them to read the Web pages. The number of Web pages to be considered will be increased sharply in a few minutes. If one had to surf the Web in order to find information needed in this way, he may end up having to visit thousands of pages. The uncontrolled vast information on 
the Internet may not be meaningful to people if one can not find needed information sooner. Web search engines were born out of this need.

There are three major functions of Web search engines: collecting new information, collating and extracting from that information, and presenting it in a publicly available Web interface. ${ }^{16}$ Information is collected by intelligent agents such as spiders by crawling over the Web pages via links between them. All documents found by the intelligent agents are converted and saved in databases in forms that a computer can understand and process. Each collected document is then passed through an information extraction system to extract document representatives and bibliographic information to form indexes. ${ }^{16,22}$ These indexes will be grouped based on the similarity of documents. The search engines entertain user queries and provide a list of relevant documents in a user-friendly format.

Google believes every hyperlink embedded in a Web page is a citation to the other Web page. ${ }^{4}$ The PageRank system used by Google shows how many Web pages and sites link to a page. It reflects the relative importance of a site. The Google system performs a type of full text searches that look for keywords within the title, abstract, and full text of an article. PageRank takes a very important role in the system to prioritize the results of Web keyword searches. ${ }^{3}$ The PageRank algorithm enables Google to dominate other Web search engines in terms of usage.

\subsection{Web-based Learning Game}

Prensky ${ }^{20}$ claims that the success of learning usually depends upon motivation. Motivation encourages students to continue their studies. Video and computer games provide the pleasure and motivation of learning to young people who are already familiar with digital technology. Jong et al. ${ }^{13}$ depicted that game-based learning could reduce the frequently received negative feedback of Web-based learning regarding no motivation. Dziabenko and Pivec et al. ${ }^{6}$ designed a Web-based game for learning and showed that it can be very helpful for adult vocational or university-level learning as well as teaching children. Games adapted for learning are capable of helping students become interested in learning while stimulating students' motivation towards learning. If game-based learning is combined with the traditional methods of learning, the effectiveness of the learning could be greatly improved. ${ }^{13}$

Web-based games mostly depend on Web technology. Web technology makes it possible to connect to Web-based games from anywhere the Internet is available and to play the games with others. Many of the features of the application of a Web-based game are run on Web servers. Each screen of a Web-based game works like a Web page. ${ }^{6}$ A player usually visits the homepage of the game and clicks the link of the game application to play. The speed of the Internet is one of the most important factors to consider in the design of a Web-based game. Most Web-based games pursue very simple graphic images to reduce the download times.

The concept of a Web-based learning game is extended from the game-based learning by employing the Web. ${ }^{30}$ It provides students with the contents of learning through Web-based games. Raychaudhuri ${ }^{21}$ presented a Web-based game to simulate a supply chain concerning the procurement and supply of oil. This game was intended to serve as a useful learning tool for logistics managers and students in logistics or supply chain courses. Shang et al. ${ }^{23}$ developed a Webbased learning game called FARMTASIA, a simulation game of farming, in order to implement a learning framework VISOLE. Sheth ${ }^{24}$ instanced a Web-based learning game called Urban Quest to explicate avatars in online learning. The purpose of the game is to enable children to understand safety in their home and around the city. Michaelson et al. ${ }^{17}$ developed a Web-based learning game for finance education of undergraduates in the FINESSE project. The aim of the game is to provide students with a Web-based learning environment to manage a portfolio of securities with real-time share price data.

A treasure hunt was originally an outdoor activity for children to find objects hidden by others. The first team to bring all the items in the list wins. To maximize enjoyment of the game, "objects should be difficult enough to challenge the children's ingenuity, but not beyond their reach." 2 Marcus and Beck ${ }^{15}$ suggested a treasure hunt model to introduce intimately the campus library to students. The treasure hunt model engages the students in solving a mystery through the library with a series of clues. This model provides a problem-solving approach to learning.

As for online activity of the treasure hunt, Skelly ${ }^{25}$ defined that "a treasure hunt is an activity in which one searches for clues and answers." Hamelin ${ }^{9}$ described an experiment of inquiry-based learning in the form of a treasure hunt on the Web. In the experiment, students being given the treasure hunt assignment with a series of questions tried to find the answers on the Web using search engines. He showed that the treasure hunt in the inquiry-based learning could be a very effective tool to develop searching abilities using the Internet. 
Blas et al. ${ }^{1}$ employed an online treasure hunt game in the SEE project that furnished students with a virtual learning environment based on 3D graphics. Students, represented by avatars, get online meetings together and discuss previously studied themes under the active supervision of a guide, also represented by an avatar, in a virtual museum. After the discussion, they play the treasure hunt to find solution to cultural riddles provided by the museum. As presented in the SEE project, the treasure hunt is very good at encouraging students to review their learning with fun and thrills.

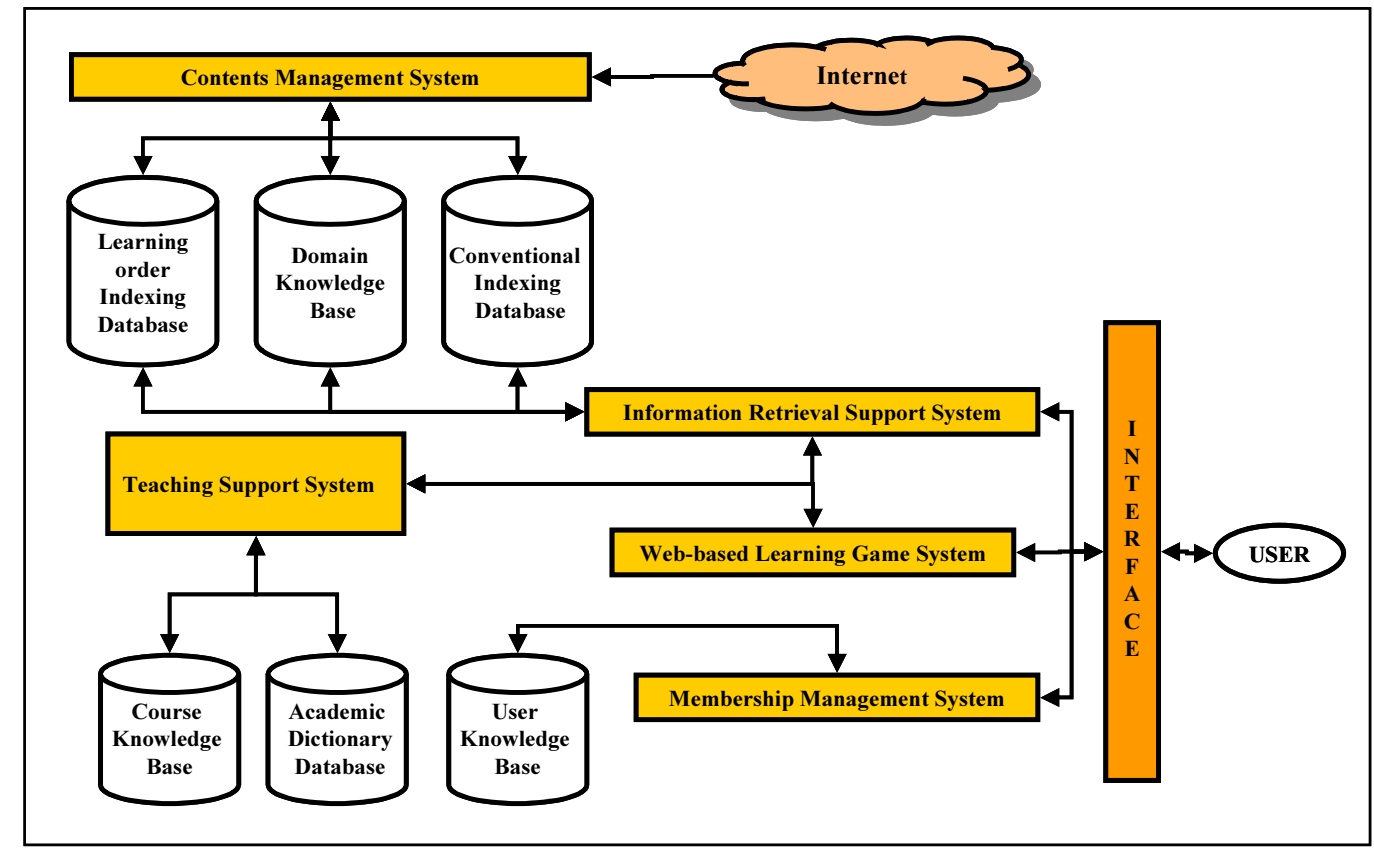

Figure 1. An Architecture of Web-based Learning Support Systems.

\section{A TREASURE HUNT GAME ENHANCED WEB-BASED LEARNING SUPPORT SYSTEM}

We will present the architecture and major subsystem of a Web-based learning support system enhanced with online games and learning oriented search engine.

\subsection{An Architecture of the WLSS}

The architechure of the WLSS is presented in Figure 1. The user of the system are students, instructors, and evaluators. Users access the system via an interface. The interactive user interface contains mark up language codes for providing graphical user interface. Users will interact with the Web-based information retrieval support subsystem, Web-based learning game subsystem, and membership management subsystem.

The membership management subsystem manages various members such as present, past and affiliate members. One of its most important features is the identification and authentication of each user and gives authentications to enable users to access available services. For example, if a teacher is present, the membership management subsystem will create a teaching support agent to facilitate the communication with teaching support subsystem. The user knowledge base contains users' profile.

The Web-based information retrieval support subsystem interacts the Web-based learning game subsystem with a learning support agent. A teaching support agent facilitates interaction, communication, and data transfer between the Webbased information retrieval subsystem and the teaching support subsystem.

The teaching support subsystem helps teachers define course descriptions and concepts. The subsystem provides a graphical user interface for the teacher to define and update the learning order of the course textbook. The course-related information is stored in the course knowledge base. 


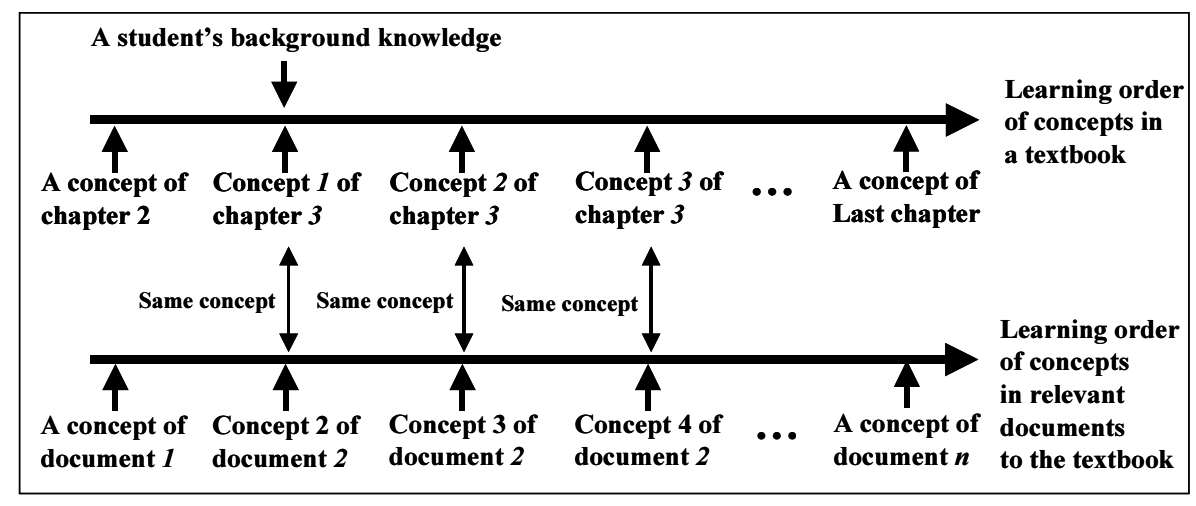

Figure 2. Learning order of concepts in a textbook and learning order of concepts in relevant documents to the textbook.

The content management subsystem mainly performs the phases of learning order indexing. It manipulates acquired documents by Web intelligent agents which crawl through the Web. The domain knowledge base contains local information such as bibliographic information, related keywords, and links. It refers to the Internet-based remote information. The conventional indexing database contains document representatives ${ }^{22}$ or indices to represent documents in domain knowledge base. The learning order indexing database contains term relationship graphs that represent documents, and their values of relative difficulty ratio.

The information retrieval support subsystem is a central component in the architecture which facilitates interaction among all subsystems. It includes search functionality and provides information to the learning game subsystem.

Two of the major subsystems of the WLSS are the Web-based learning game and the learning-oriented Web search engine. The Web-based learning game enables students to get interested in learning. It allows them to review their studies, to do self-tests, and to check their understanding on certain courses and lectures by playing a treasure hunt game. In addition, the learning-oriented Web search engine helps students find documents that are related and suitable to their studies. It provides each student with a list of documents that are ordered according to the relative difficulty of documents compared to the student's background knowledge.

\subsection{Learning Order Indexing}

The learning-oriented Web search engine is based on the creation of learning order indexing (LOI). Learning order of objects (e.g., significant words, topics, concepts, educational materials, information units, documents, functions, commands, etc.) indicates the correct order in which a student is supposed to learn the other objects that remain after learning one object. ${ }^{12}$ LOI considers the learning order relationship between two relevant objects in order to reflect user preference. ${ }^{31}$ In other words, the learning order relationship between two relevant objects represents which object is more relevant than another. Figure 2 shows an example of the learning order of concepts in a textbook and an example of the learning order of concepts in relevant documents to the textbook. The learning order relationship can be expressed by a set of term relationship graphs (TRG).

As Figure 3 shows, a TRG is a hierarchy graph that represents the learning order relationships between terms of a document. For a term relationship graph $G$, if $V$ is a set of vertices or nodes, and $A$ is a set of ordered pairs of vertices, $G$ can be expressed as: $G=(V, A)$. Each vertex contains a significant term, a level of hierarchy whose top level is 1 , and a number of sentences needed to explicate the term. Therefore, $V$ is expressed a set of triplets of the form (term, level, number of sentences):

$$
V=(t, l, s)
$$

where a term $t$ is one of salient words or phrases in a document, $l$ is a level of hierarchy, and $s$ is a number of sentences needed to describe the term $t$ in the document. An arrow between two vertices points the vertex that contains the next occurrence of a term within the learning order of terms.

The learning order relationship between two relevant objects can also determine which concept is more difficult than another. Students naturally feel that the posterior concepts in a course textbook are more difficult than the prior concepts, for 


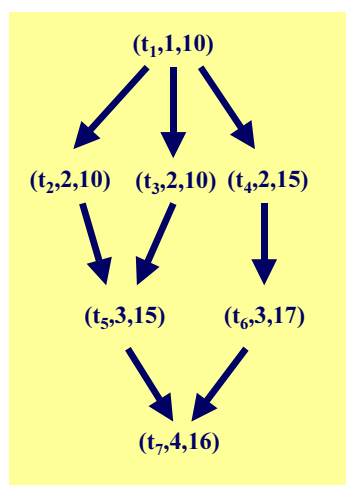

Figure 3. An example of a term relationship graph.

the posterior concepts require students to know about the prior concepts first. In addition, students tend to make estimates and educated guesses ${ }^{9}$ of what a new concept is mentioned about in a class, and they feel easy if the concept is very close to what they guessed. As shown in Figure 4, the more a concept is different from what a student has known, the more the concept becomes difficult to guess and understand. Thus, for a course, the last concept in the learning order of concepts becomes the most different and difficult concept at any time. Likewise, the more an object is different from what a student has known, the more the object becomes difficult to guess and understand. Therefore, in the learning order indexing, the similarity between objects can be represented by relative difficulty ratio. A relative difficulty ratio is a normalized value that indicates the relative difficulty of an object with regard to a student's background knowledge.
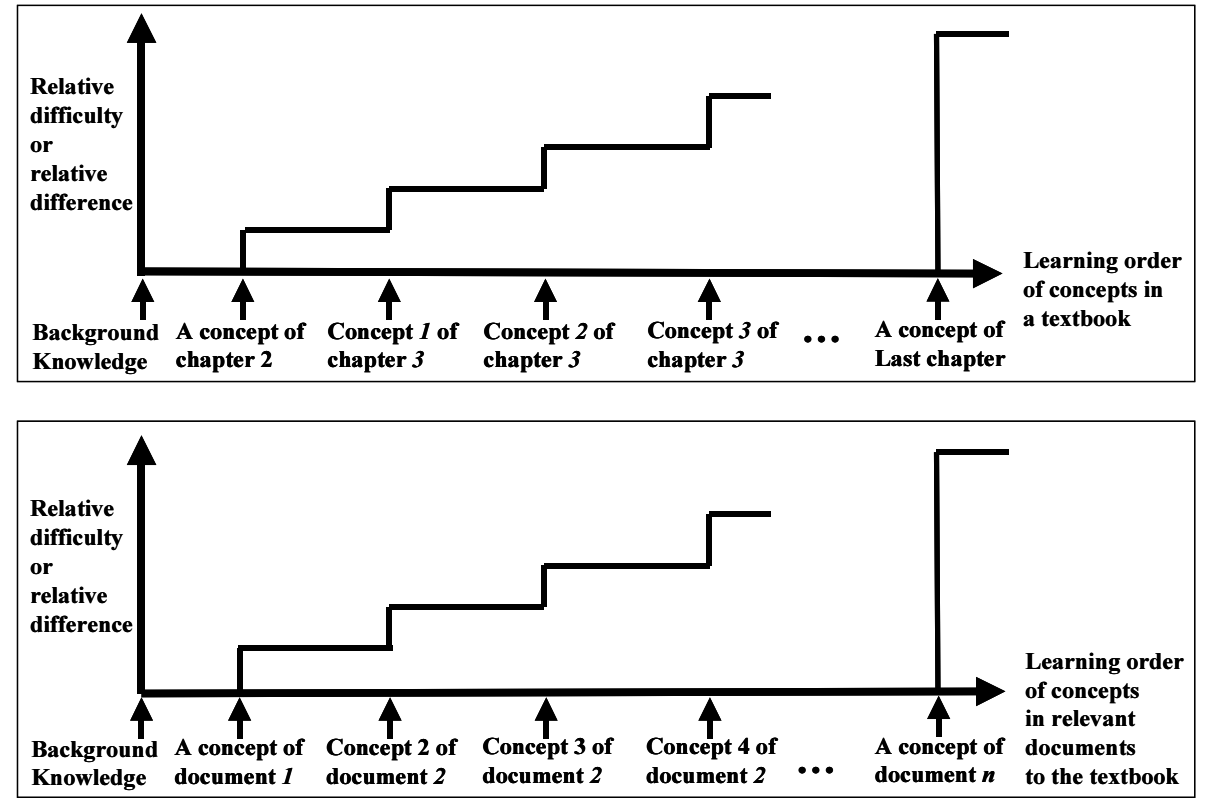

Figure 4. Relative difficulty or relative difference for learning order of concepts in a textbook, and relative difficulty or relative difference for learning order of concepts in relevant documents to the textbook.

It needs roughly five steps to generate learning order indexing. Firstly, the learning order for all concepts in a textbook is established. Secondly, a collection of relevant documents to the textbook is obtained by using the conventional indexing. Thirdly, the learning order for all relevant concepts to the textbook in the documents is established. Fourthly, each concept of the textbook with the learning order is compared to all the relevant concepts of the documents. Lastly, the documents with the most suitable concepts are grouped together.

The generation of LOI can be illustrated with Figure 2. The upper part is obtained in step 1 and the lower part in step 
3. The concept 2,3 , and 4 of document 2 are the same as the concept 1,2 , and 3 of chapter 3 in the textbook, respectively. The relative learning order of the concepts of document 2 with regard to the background knowledge is the same as the relative learning order of the concepts of the chapter 3 in the textbook. The bidirectional arrows in the middle (with label of same concept) are obtained in step 4. All documents have concepts same as concept 1, 2, and 3 of chapter 3 will be grouped with document 2 together in the last step.

In addition, as the background knowledge in Figure 2 compares to it in Figure 4, it shows the former background knowledge is improved more by learning.

LOI requires a special query format, learning order query. A learning order query is composed of 1) learning order relationship between significant words (or phrases), and 2) maximum pages needed to explicate each word or phrase. To prepare a learning order query, one has to use the learning order operator $(<)$ for the learning order relationship and square brackets ([,]) for the maximum pages. The number of maximum pages is internally converted to the number of maximum sentences. The default query mode in the learning order search doesn't take into account the maximum pages, that is if the query 'data communication' network ethernet is submitted, then the interpreted query is surely

'data communication' [0] < network[0] < ethernet [0] which means finding the phrase data communication that is described ahead of the word network that is described ahead of the word ethernet in a document without any consideration of the maximum pages.

\subsection{Treasure Hunt Game}

The Web-based learning game subsystem employs a treasure hunt game. The treasure hunt game is a Web-based singleuser game. Its game genre is an adventure game. A player usually tries to find hidden treasure among fake treasure with given clues while trying to overcome some difficulties and looking for the treasure. One of the ways to get the treasure is to unearth them. The other way is to explore treasure islands and dungeons. To clear each stage of the game he has to get enough points to level up to the next stage while staying alive. Real treasure gives him points, but fake treasure gives him some penalties. Some equipment, tools, and aids are needed not only to find and unearth treasure, but also to deal with some threats such as wild animals and pirates. The player can exchange these things with his points. Sometimes, Non-Player Characters (NPC) guide the player and give the clues to him. If the player cannot find any clue for the treasure, he must get help from the library that provides the information about the treasure.

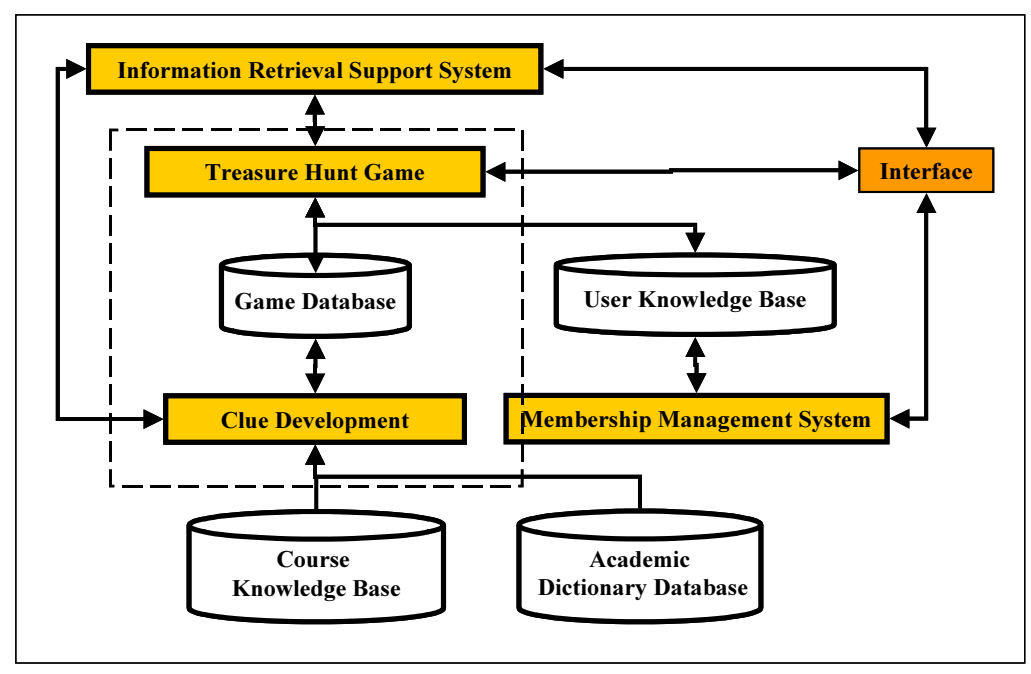

Figure 5. The Architecture of Web-based Learning Game Subsystem.

Each game may consist of different skill levels. If the player clears a game stage, his game level will be increased by one. In the end of each stage, the player has to attend a quiz event. If the player is good at the quiz, he is allowed to the next stage. The game system considers the player's weak points as it composes his next stage and incorporates the weak points in the storyline of the next stage. 
In the Web-based learning game, treasures are concepts to be learnt, and fake treasure are the concepts unrelated to clues. The clue is made of the description of the concept. A NPC personifies a concept. All the names, including NPCs and places in the game world, consist of relevant words to the concepts to look for. While a player accompanies an NPC on the way to a place where a concept seems to be buried, the player can start to learn rumors about the concept from the NPC. The rumor must be a key clue to find the concept. The player can also learn about how to use the Web search engine to find relevant documents through the library event in the game. The concepts with the same hierarchical level in the term relationship graph of a textbook as what the player wants to discover become the names of threats or the fake concepts. On the other hand, the concepts of the different levels of the TRG become aids. The quiz event of the end of each stage encourages the player to review the concepts having appeared in the stage. The game level of a student indicates his understanding level of the course. The TRG of the textbook can be applied to a treasure map.

As shown in Figure 5, the clue development would be one of main components in the Web-based learning game. It automatically generates the clues and quizzes with regards to the concepts using all related information about the concepts from the Web search anent, course knowledge base and academic dictionary database. The available information can be titles, descriptions, significant words, assumptions, formulas, theorems, their relationship with other concepts, and even the page number of documents containing the concepts. In addition, the clue development composes new storylines based on either the user's skill level or new textbook. It finds out for each game stage how many chances are available to give clues including events and conversations between NPCs and a player. It randomly decides which terms are real treasure and fake treasure. The clues are then distributed to the events and NPCs and the engine names all places on the way to where the treasures are buried. The names may be referred in the conversations and the events.

\section{A DEMONSTRATIVE EXAMPLE FOR A DATA COMMUNICATION COURSE}

This section shows an example to use WLSS with the Data Communications course. The Contents Management Engine reads the textbook in electronic format including Table of Contents section, in which terms of the titles are mostly listed in learning order. The engine establishes a term relationship graph, or TRG of the textbook as shown in Figure 6 . All the relevant documents in accordance with the terms in the TRG of the textbook are collected. Each TRG for those documents is generated.

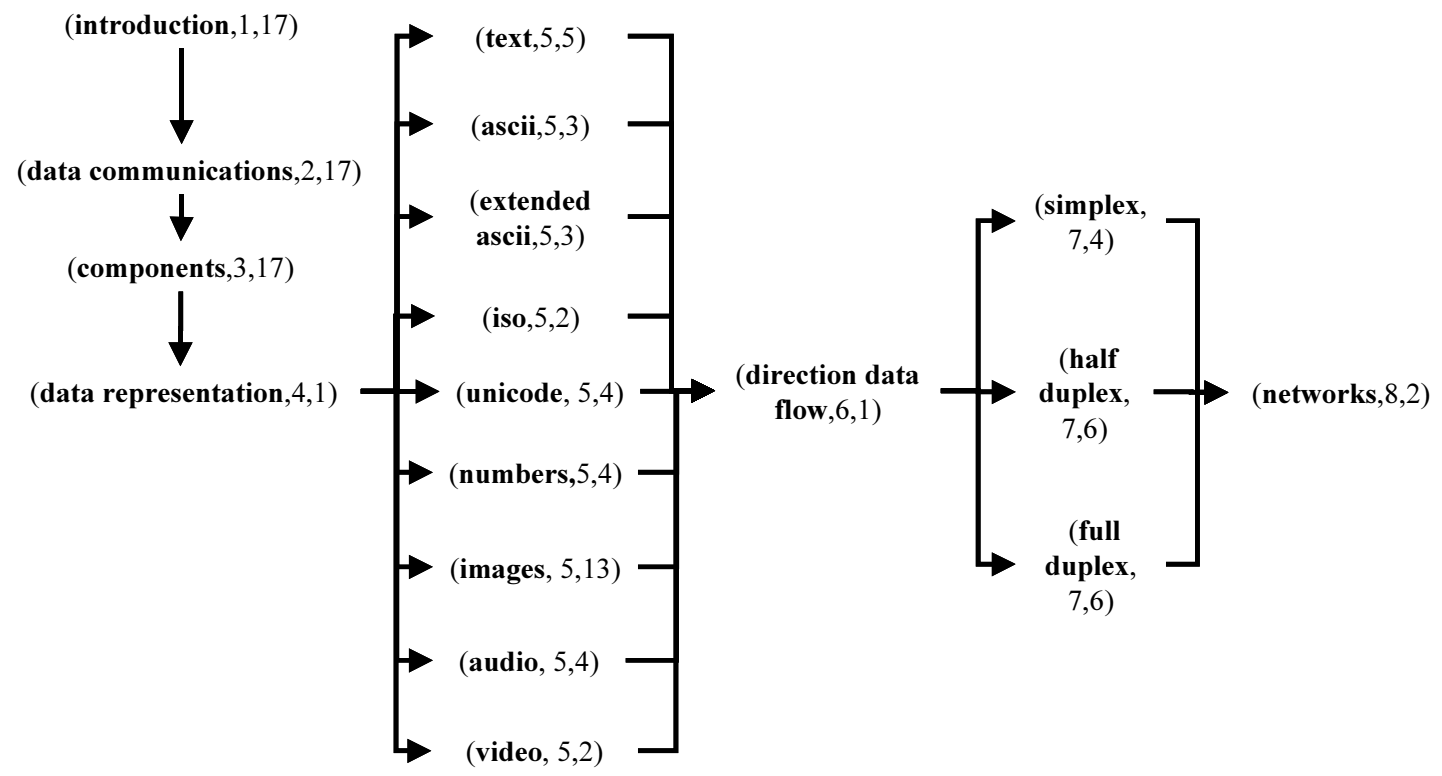

Figure 6. Part of a term relationship graph for the Textbook of Data Communications Course.

Figure 6 shows the beginning part of the TRG for the textbook of a Data Communications course. According to Equation 1, the introduction concept is expressed as (introduction, 1, 17). Its hierarchical level is 1 , for the node is on the top level of the hierarchy. The number of sentences is 17 . It means 17 sentences are required to explicate the term 
introduction in the textbook. Components concept is on level 3, and it needs 17 sentences also. Therefore, it is described as (components, 3,17 ) in the TRG. The lowest in this graph is (networks, 8,2$)$. The learning order in the graph can be expressed as:

$$
\begin{aligned}
& \text { introduction }<\text { data communications }<\text { components }<\text { data representation } \\
& <(\text { text, ascii, extended ascii, unicode, iso, numbers, images, audio, video }) \\
& <\text { direction data flow }<(\text { simplex, half duplex, full duplex })<\text { networks, }
\end{aligned}
$$

where ' $<$ ' is the learning order operator. As a matter of fact, the sequence is a partial order in most cases.

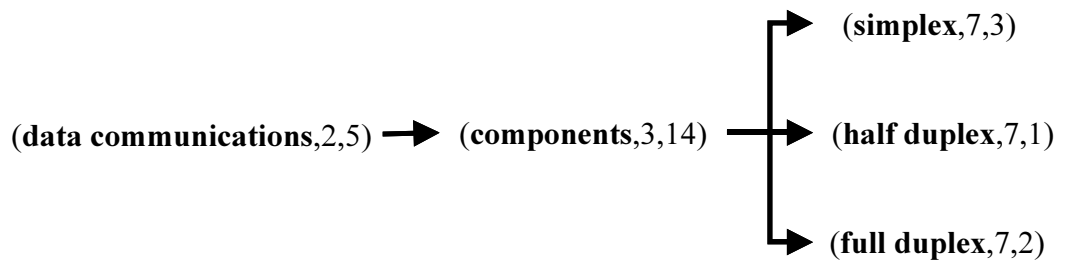

Figure 7. A Part of a term relationship graph for a relevant document to the textbook.

Figure 7 shows a TRG of a document that is supposed to be one of the most relevant documents among over 190,000 documents searched with Google to the textbook. This is only if a student's background knowledge about the class is just enough to understand the phrase Data Communications. To establish the TRG, all the significant terms and phrases in the document are compared with the terms from the introduction node in Figure 6. A node of the TRG in the document consists of the matched term, the level of the term in Figure 6, and the number of sentences to explicate the term in the document. In Figure 7, no term introduction is found in the document, but the phrase Data Communications is found ahead of the term components in the document. The learning order in the graph can be described by:

$$
\text { data communications < components < (simplex, half duplex, full duplex }) \text {. }
$$

The term relationship graph of Figure 6 is a basis to generate clues and quizzes, and to compose storylines for stage 1 of the treasure hunt game as shown in table. If there are one event and two NPCs in order of occurrence at the stage 1 and real treasures are extended ascii and image, as shown in Table 1, the NPCs are named Data Communications and Components, and fake treasures are unicode, iso, numbers, audio, and video. Terms Text and Ascii become names of some treats. In this case, the hierarchical levels of the terms of the real treasures are 5. On the other hand, the aids' names can be as follows: introduction, data communications, components, data representation, direction data flow, networks. This occurs because the levels of the terms are different from the levels of the real treasures extended ascii and image.

At the beginning of the stage 1, Event 1 in Figure 8 gives a player a quest for the treasure. From the quest, the player knows of some information about the treasure to look for. He realizes to meet an NPC that represents Data Communications is the first thing. The NPC recommends him to find and meet another NPC Components with the information about the location of Components. The player could find the NPC Components at a location representing Protocol, which is derived from the description of components in Academic Dictionary Database. The NPC Components provides the

\begin{tabular}{|c|l|}
\hline Game Objects & Learning Concepts \\
\hline Event 1 & Introduction \\
\hline NPC 1 & Data communications \\
\hline NPC 2 & Components \\
\hline Place 1 & Protocol \\
\hline Place 2 & $\begin{array}{l}\text { Data representation, Extended ASCII, Unicode, } \\
\text { ISO, Numbers, Images, Audio, Video }\end{array}$ \\
\hline Threat 1 & Text \\
\hline Threat 2 & ASCII \\
\hline
\end{tabular}

Table 1. Examples of Game Objects and Corresponding Learning Concepts. 


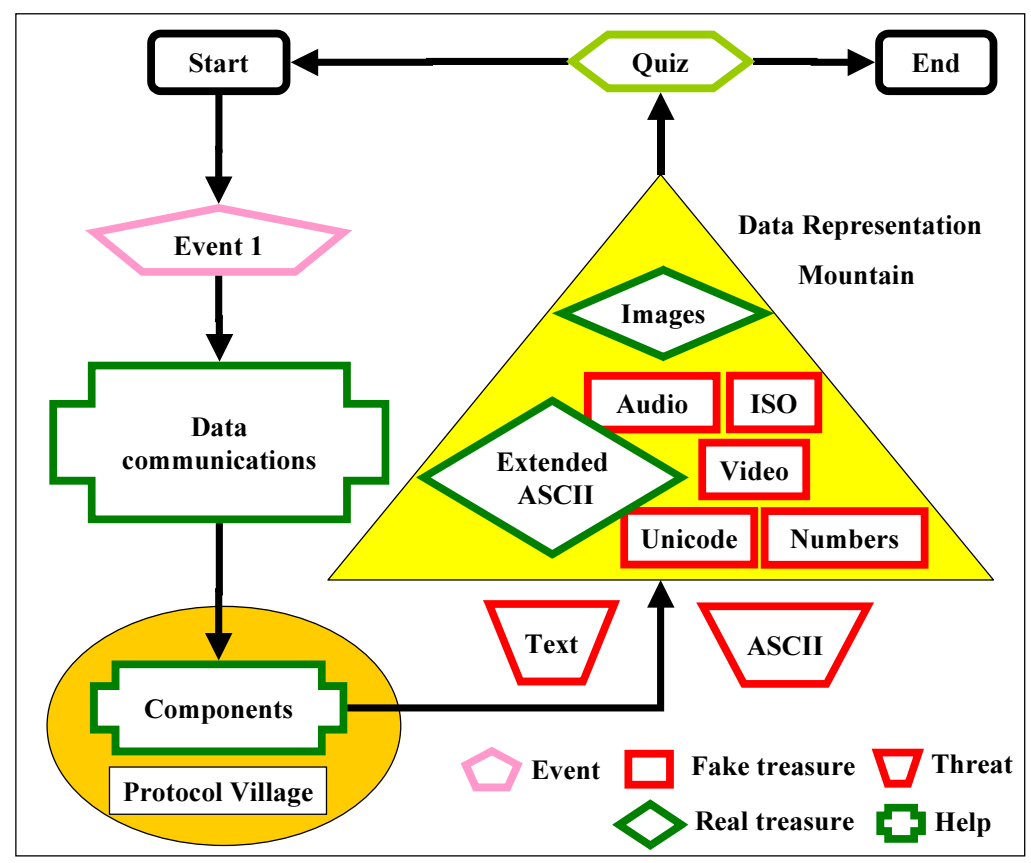

Figure 8. A Treasure Map.

player with final clues about real treasures, extended ascii and image. However, the player may have to encounter some threads if he didn't have enough points to pass the entrance. The purpose of threats is to make sure the player understand some basic concepts such as text and ascii. Points will be deducted if the right answers can not be provided. If a player's points are lower than a threshold he has to play the game from stage 1 again.

The goal of the player is to reach a location representing concepts and learn from treasures. Points be deducted if a fake treasure is found. Quiz is the last event before a player gains a level ro stage. After the player finishes the quiz event and has enough points, he may go to the next stage of the game.

\section{CONCLUSION}

We have discussed the needs for Web-based learning support systems. The architecture of a particular WLSS system is presented. The system provides students with well-organized knowledge and highly motivating learning environment through two major subsystems, learning-oriented Web search and Web-based learning game. A Web-based learning game subsystem furnishes students with motivations of learning and an easy way to learn. A treasure hunt game is used as the media for such learning purpose. The game is generated with a clue development engine. The second unique feature of the WLSS is the learning-oriented Web search. The learning order is indexed based on relevance and difficulty of documents. The difficulty levels are based on an individual student's knowledge background. Learning-oriented Web search would provide students with suitable documents for their own learning needs.

\section{REFERENCES}

1. N. D. Blas, P. Paolini, C. Poggi, Learning by Playing An Edutainment 3D Environment for Schools, World Conference on Educational Multimedia, Hypermedia and Telecommunications, Lugano, Switzerland, 1313-1320, 2004.

2. G. C. Bowker, S. L. Star, Sorting Things Out: Classification and Its Consequences, The MIT Press, Massachusetts London, England, 1999.

3. S. Brin and L. Page, The Anatomy of a Large-Scale Hypertextual Web Search Engine, Computer Networks and ISDN Systems, 30(1-7):107-117, 1998.

4. M. Busby, Learn Google, Wordware Publishing, 2004. 
5. P. F. Drucker, Managing in the Next Society, Truman Talley Books, 2002.

6. O. Dziabenko, M. Pivec, C. Bouras, V. Igglesis, V. Kapoulas, and I. Misedakis, A Web-Based Game For Supporting Game-Based Learning, GAME-ON 2003, London, England, 111-118, 2003.

7. L. Fan and Y. Y. Yao, Web-based Learning Support Systems, WI/IAT 2003 Workshop on Applications, Products and Services of Web-based Support Systems, Halifax, Canada, 43-48, 2003.

8. M. Gordon and P. Pathak, Finding information on the World Wide Web: the retrieval effectiveness of search engines, Information Processing and Management, 35(2):141-180, 1999.

9. D. Hamelin, Searching the Web to Develop Inquiry and Collaborative Skills, ACM SIGCSE Bulletin, 36(4):76-79, 2004.

10. M. Hanus and F. Huch, An open system to support web-based learning, Proceedings of the 12th International Workshop on Functional and (Constraint) Logic Programming, 269-282, 2003.

11. H. Huang, Toward constructive for adult learners in online learning Environments, British Journal of Educational Technology, 33(1):27-37, 2002.

12. W. P. Jones and G. W. Furnas, Pictures of relevance: A geometric analysis of similarity measures, Journal of the American Society for Information Science, 38(6):420-442, 1987.

13. M. S. Y. Jong, J. J. Shang, F. L. Lee, J. H. M. Lee, and H. Y. Law, Learning Online: A Comparative Study of a Situated Game-Based Approach and a Traditional Web-Based Approach, LNCS, 3942:541-551, 2006.

14. Kinshuk, Web-based learning and teaching technologies: Opportunities and challenges, Online Information Review, 26(1):61-62, 2002.

15. S. Marcus and S. Beck, A Library Adventure: Comparing a Treasure Hunt with a Traditional Freshman Orientation Tour, College \& Research Libraries, 64(1):23-44, 2003.

16. A. McCallum, K. Nigam, J. Rennie, and K. Seymore, Building Domain-Specific Search Engines with Machine Learning Techniques, Proceedings of AAAI-99 Spring Symposium on Intelligent Agents in Cyberspace, 28-39, 1999.

17. R. Michaelson, C. Helliar, D. Power, and D. Sinclair, Evaluating FINESSE: a case study in group-based CAL, Computers and Education, 37(1):67-80, 2001.

18. A. Parkes, Is a picture worth a thousand words? The use of non-text items in Information Systems Research, Australian Journal of Information Systems, 8(1):64-72, 2000.

19. D.J. Power and S. Kaparthi, Building Web-based decision support systems, Studies in Informatics and Control, 11:291-302, 2002.

20. M. Prensky, Digital Game-Based Learning, ACM Computers in Entertainment, 1(1):21-21, 2003.

21. S. Raychaudhuri, Web-based Oil Supply Chain Game, Simulation \& Gaming: An International Journal of Theory, Practice and Research, In press.

22. C. J. V. Rijsbergen, Information Retrieval, Dept. of Computer Science, University of Glasgow, 1979.

23. J. J. Shang, M. S. Y. Jong, F. L. Lee, and J. H. M. Lee, VISOLE: A New Game-based Situated Learning Paradigm, Proceedings of the Sixth International Conference on Advanced Learning Technologies, 1082-1083, 2006.

24. R. Sheth, Avatar Technology: Giving a Face to the e-Learning Interface, The eLearning Developers' Journal, 1-10, August 25, 2003.

25. L. M. Skelly, Is Your Student Project Better Than a Blackline Master?, 2006 MACUL Conference Handouts, Grand Rapids, MI, USA, 2006.

26. J. T. Yao, Design of Web-based Support Systems, Proceedings of the 8th International Conference on Computer Science and Informatics (CSI), Salt Lake City, USA, 349-352, 2005.

27. J. T. Yao and Y. Y. Yao, Web-based information retrieval support systems: building research tools for scientists in the new information age, Proceedings of the IEEE/WIC International Conference on Web Intelligence, 570-573, 2003.

28. J. T. Yao and Y. Y. Yao, Web-based support systems, Proceedings of 2003 WI/IAT Workshop on Applications, Products and Services of Web-based Support System, 1-5, 2003.

29. Y. Yang and G.Y. Wang, An Evaluation Model for Web-Based Learning Support Systems, Proceedings of IEEE/WIC/ACM International Conference on Web Intelligence, 680-683, 2005.

30. R. M. Young, Internet-Based Games, CRC Press LLC, Boca Raton, FL, USA, 2001.

31. S. K. M. Wong and Y. Y. Yao, Query Formulation in Linear Retrieval Models, Journal of the American Society for Information Science, 41(5):334-341, 1990. 